\title{
Response of Fusarium thapsinum to Sorghum brown midrib Lines and to Phenolic Metabolites
}

Deanna L. Funnell-Harris, Grain, Forage, and Bioenergy Research Unit (GFBRU), United States Department of Agriculture-Agricultural Research Service (USDA-ARS), and Department of Plant Pathology, University of Nebraska, Lincoln 68583-0937; and Scott E. Sattler and Jeffrey F. Pedersen, GFBRU USDA-ARS and Department of Agronomy and Horticulture, University of Nebraska, Lincoln

\begin{abstract}
Funnell-Harris, D. L., Sattler, S. E., and Pedersen, J. F. 2014. Response of Fusarium thapsinum to sorghum brown midrib lines and to phenolic metabolites. Plant Dis. 98:1300-1308.

Sorghum lines were bred for reduced lignin for cellulosic bioenergy uses, through the incorporation of brown midrib (bmr)6 or -12 into two backgrounds (RTx430 and Wheatland) as either single or doublemutant lines. When these lines were assessed for resistance to Fusarium thapsinum stalk rot, a cause of lodging, they were as resistant to $F$. thapsinum as the near-isogenic wild type. Peduncles of newly identified $b m r$ lines from an ethyl-methanesulfonate-mutagenized population, inoculated with $F$. thapsinum, were as resistant as the wild-type line, BTx623. One $b m r$ line (1107) had significantly smaller mean lesion lengths than BTx623, suggesting that a mutation is associ-

ated with reduced susceptibility. Growing $F$. thapsinum on medium with ferulic, vanillic, sinapic, syringic, and caffeic acids (phenolic compounds derived from the lignin pathway and elevated in different $b m r$ lines) indicated that $F$. thapsinum was tolerant to these compounds. When eight other sorghum fungi were tested for response to the presence of these compounds, ferulic acid inhibited these fungi. Most of the phenolics inhibited $F$. verticillioides and $F$. proliferatum. Accumulation of phenolic metabolites in $b m r$ plants may inhibit growth of some sorghum pathogens, while other factors such as aromatic phytoalexins or salicylic acid may be involved in resistance to $F$. thapsinum.
\end{abstract}

Sorghum (Sorghum bicolor (L.) Moench) is a valuable crop worldwide, in part due to its wide range of genetic diversity and phenotypic traits. Diversified sorghum types are available for biomass, grain, or sugar production $(24,34)$, which makes sorghum a versatile bioenergy crop $(8,41,51)$. Starch from grain sorghum and sugars from sweet sorghum are being used for ethanol production $(38,41,52)$. Sorghum biomass is expected to be included as feedstock for cellulosic biofuels in the near future $(11,49)$. Pathogens pose a serious threat to the economic sustainability of grain or biomass production for bioenergy $(23,54)$. Panicle pathogens can negatively impact grain yield, quality, and viability $(10,17,32)$. Root, stalk, and leaf pathogens can reduce biomass yield and cause lodging, which impairs harvest $(12,47)$.

The primary components of plant cell walls are the polysaccharides cellulose and hemicellulose, which can be broken down into sugars and converted to ethanol. The third major component of plant cell walls is lignin, which is a polymer made up of aromatic subunits that are cross-linked to the hemicellulose moiety. This complex construction provides strength and rigidity to prevent degradation and, in the case of vascular cell walls, allows them to conduct water under negative pressure $(1,9)$. Lignin may also play a defensive role against pathogens and insects, as a barrier to initial invasion or as an induced response to prevent spread $(2,4,48)$. Re-

Corresponding author: D. Funnell-Harris,

E-mail: Deanna.Funnell-Harris@ars.usda.gov

Mention of trade names or commercial products in this article is solely for the purpose of providing specific information and does not imply recommendation or endorsement by the United States Department of Agriculture (USDA).

* The $e$-Xtra logo stands for "electronic extra" and indicates that a supplementary table is available online.

Accepted for publication 3 April 2014.

http://dx.doi.org/10.1094/PDIS-09-13-0980-RE

This article is in the public domain and not copyrightable. It may be freely reprinted with customary crediting of the source. The American Phytopathological Society, 2014. cently, however, by using lines with reduced lignin accumulation, this plant defense role has been challenged (43).

Near-isogenic brown midrib (bmr)6 and bmr12 sorghum lines (in grain and forage) have been developed $(35,36)$. The $b m r$ mutations are described as "brown midrib" due to the reddish-brown discoloration of the midveins in maize, sorghum, and pearl millet associated with reduced lignin (44). Incorporation of bmr6 or bmr12 into elite sorghum lines resulted in significantly reduced lignin content and increased digestibility of the lignocellulose tissue for ruminant animal feed or for bioenergy uses $(31,41)$. Bmr6 encodes a cinnamyl alcohol dehydrogenase $(39,45)$ and Bmrl2 encodes caffeic acid $O$-methyltransferase (5). Both bmr6 and bmr12 alleles used in this study resulted from nonsense mutations within their respective genes, and are likely null alleles $(5,33,39,45)$. Near-isogenic double-mutant lines having both bmr6 and $b m r 12$ alleles were developed that are significantly reduced in lignin content as compared with either single $b m r$ mutant lines and have increased efficiency in ethanol conversion of the biomass $(13,37)$. Further studies using bmr6, bmr12, and bmr6 bmr12 plants showed that concentrations of both soluble (micrograms per gram dry weight) and cell-wall-bound (micrograms per gram of cell walls) phenolic compounds were altered in the $b m r$ lines compared with their wild-type counterparts (33), with bmr6 plants having the highest concentrations of free phenolic compounds overall. However, interactions were apparent between genetic background and $b m r$ mutation that resulted in significant differences in the free phenolic profiles within the same mutation in different genetic backgrounds. In addition to reduced lignin content, both $\mathrm{bmr}$ mutants also resulted in altered monomeric composition of the lignin subunits $(\mathrm{G}, \mathrm{S}$, and $\mathrm{H})$ relative to wild-type (33).

Using bmr6 and bmr12 lines in five genetic backgrounds, it was previously shown that $b m r$ lines were not more susceptible (e.g., no increased colonization) than the wild type, counter to previously held concepts $(16,19)$. Fusarium spp. infected grain of bmr6 and bmr12 lines less frequently than wild-type lines. Two Fusarium spp. that commonly infect wild-type grain, Fusarium proliferatum and an $F$. incarnatum- $F$. equiseti species complex genotype, were significantly reduced or absent, respectively, in bmrl2 grain (19). When peduncles (the upper part of the stalk that supports the head) were inoculated with Fusarium thapsinum Klittich, J.F. Leslie, P.E. 
Nelson \& Marasas 1997 (current name Gibberella thapsina Klittich, J.F. Leslie, P.E. Nelson \& Marasas), mean lesion length was significantly smaller on $\mathrm{bmr}$ plants across genetic backgrounds than on wild-type plants (16). Additionally, fungal growth from dissected peduncles inoculated with six different fungal species showed that growth within and at the border of lesions formed on bmrl2 plants was significantly greater than from that resulting on wild-type plants (19). These results suggested that bmr12 plants may have reduced plant responses, such as anthocyanin pigmentation, resulting in smaller visible lesions $(19,20)$.

In the present study, a basal stalk inoculation protocol was developed to more directly assess the effects of $F$. thapsinum stalk infection on lodging. Near-isogenic lines bmr6 and bmr12 and bmr6 bmrl2 double-mutant plants in two genetic backgrounds (RTx430 and 'Wheatland') were tested for response to this stalk rot pathogen. Seven new $b m r$ mutants, including the recently characterized $b m r 2-2$ mutant (40), were also tested for response to peduncle inoculations compared with wild-type (BTx623) plants. As described above, bmr lines have altered levels of phenolic metabolites compared with the wild type. These compounds may have inhibitory effects on fungi $(6,21,27)$. Therefore, $F$. thapsinum and eight other fungal pathogens found in grain, leaves, or stalks of sorghum were tested for growth on phenolic metabolites.

These experiments were conducted to test the following hypotheses. First, bmr6, bmr12, and bmr6 bmr12 double-mutant lines are not more susceptible to $F$. thapsinum stalk inoculations than near-isogenic wild-type lines. Second, the new bmr lines are not more susceptible to $F$. thapsinum peduncle inoculations than the near-isogenic wild-type line. Finally, to address whether phenolic compounds increased in $b m r$ lines provide a potential factor involved in resistance to sorghum pathogens, the third hypothesis is that sorghum fungal pathogens will be sensitive to at least one phenolic compound derived from the lignin biosynthesis pathway.

\section{Materials and Methods}

Fungal isolates. The fungal isolates utilized in this study are as follows. G. thapsina isolate numbers FRC-M-3790 and H03S-11-9 will be referred to by the more commonly used anamorph, $F$. thapsinum. The two isolates are similar in virulence on sorghum (19); FRC-M-3790 is a type isolate for the species, originally isolated from Mississippi (26), and H03S-11-9 was obtained in Lincoln, NE, and is customarily used for greenhouse inoculations. $G$. fujikuroi var. fujikuroi (Sawada) Wollenw. (FRC-M-1141), Haematonectria haematococca (Berk. \& Broome) Samuels \& Rossman (FRC-M-0900), and Cochliobolus lunatus R.R. Nelson \& F.A. Haasis (LP09-1) will be referred to by the more commonly used names $F$. verticillioides (Sacc.) Nirenberg, $F$. solani (Mart.) Sacc. 1881, and Curvularia lunata (Wakker) Boedijn 1933, respectively. Alternaria sp. (H02-755S), Fusarium armeniacum (G.A. Forbes, Windels \& L.W. Burgess) L.W. Burgess \& Summerell (H02-781L-5b), Fusarium pallidoroseum (Cooke) Sacc. 1886 (M03-11261L-9), Fusarium proliferatum (Matsush.) Nirenberg 1976 (M02-7013S-2), and Macrophomina phaseolina (Tassi) Gold 1947 (MP01-001) also were used. Isolates numbered with "FRC" (F. thapsinum, $F$. verticillioides, and $F$. solani) were purchased from the Fusarium Research Center (Department of Plant Pathology, Penn State University). C. lunata and M. phaseolina isolates were generous gifts from L. K. Prom and G. Odvody, respectively. F. verticillioides, $F$. thapsinum isolate FRC-M-3790, and $M$. phaseolina were isolated from sorghum stalks. $F$. thapsinum isolate H03S-11-9, F. proliferatum, $C$. lunata, and Alternaria sp. were isolated from grain. F. armeniacum and $F$. pallidoroseum were isolated from sorghum leaves and $F$. solani was isolated from sorghum field soil. Working cultures were maintained on one-half strength potato dextrose agar (PDA; prepared with potato dextrose broth [PDB]; Becton, Dickinson and Co.). Long-term storage cultures were silica gel with sterile skim milk (stored at $4{ }^{\circ} \mathrm{C}$ ), $40 \%$ glycerol, $40 \%$ sterile skim milk (stored at $-80^{\circ} \mathrm{C}$ ), and PDA slant cultures (stored at $\left.4^{\circ} \mathrm{C}\right)(20)$.
F. thapsinum stalk inoculations of near-isogenic $b m r$ lines. All inoculations were conducted at the University of Nebraska, Lincoln, Department of Plant Pathology greenhouse. A sorghum stalk inoculation technique was optimized for $F$. thapsinum. The fungal culture (isolate H03S-11-9) was prepared by inoculating sterile toothpicks in $5 \mathrm{ml}$ of sterile full-strength PDB with a mycelium-covered agar plug from a PDA plate culture grown for 7 days. The broth-and-toothpick cultures were incubated for 2 weeks at $25^{\circ} \mathrm{C}(22)$. To account for wound responses, control inoculations were conducted with sterile toothpicks incubated in sterile broth.

Wheatland plants were used in developing this stalk inoculation protocol. Greenhouse-produced seed were sown into $25.4-\mathrm{cm}$ diameter pots containing pasteurized soil mix (one part sand, one part coarse vermiculite, one part top soil, and two parts shredded peat moss). Seedlings were culled to one plant per pot. The assay was optimized by testing for inoculation site, inoculation time, and days after inoculation for disease progress assessment. For the first preliminary assay, two inoculation sites were attempted: brace roots or the stalk at the second internode above the brace roots. Times of inoculation were at internode differentiation (vegetative; 8 to 12 weeks after planting), boot (12 to 13 weeks), and anthesis (14 to 15 weeks), and times of disease progress assessment to measure lesion lengths were 18 (stalk inoculations only), 25, and 42 days after inoculation (dai). Based on results of the first test, brace root inoculations were inconsistent, and neither anthesis inoculations nor the 18- and 42-dai lesion measurements enhanced mean lesion lengths. Therefore, a second test using only stalk inoculations was designed with combinations of vegetative- or bootstage inoculations and 25-, 32-, and 39-dai lesion measurements. Statistical analyses $(P=0.03)$ confirmed that the most efficient and optimal protocol was to inoculate stalks at the second internode during the vegetative stage (approximately 10 weeks after planting). Lesion measurement time was chosen at 32 dai because mean lesions from this time were slightly larger than at 25 or 39 dai, although not significantly so $(P \geq 0.14)$.

To assess response of $b m r$ near-isogenic lines to $F$. thapsinum stalk rot inoculations, wild-type, bmr6, bmr12, and bmr6 bmr12 double-mutant plants in the backgrounds RTx430 and Wheatland $(36,37)$ were inoculated with isolate H03S-11-9. Plants were grown from greenhouse-produced grain and fungal inoculum was prepared, as described above. Fungal inoculations were conducted on 10-week-old plants by gently pushing a surface-disinfested awl one-quarter of the diameter into the stalk in the middle of the second internode. A toothpick with fungal broth culture or sterile broth was inserted into the resulting hole. At 32 dai, the stalk was split and the length of the red to purple discoloration (defined as the "lesion") was measured. The experimental design was eight randomized complete blocks with 16 plants per block, combinations of two cultivars (RTx430 and Wheatland), four bmr genotypes (bmr6, bmr12, bmr6 bmr12, and the wild type), and two treatments ( $F$. thapsinum and sterile broth). Individual plants or pots were considered the experimental unit. Replications were blocked by location within the greenhouse. The experiment was conducted at three different times: repetition number 1 was conducted July through September 2009, number 2 during November 2009 through February 2010, and number 3 from May through August 2010, for a total of 24 observations. The data were analyzed using the PROC MIXED procedure of SAS/STAT software (SAS and all other SAS Institute Inc. product or service names are registered trademarks or trademarks of SAS Institute Inc. in the United States and other countries) (42). Data sets were analyzed for Levene's homogeneity of variance (HoV) and appropriate adjustments were incorporated using the REPEATED/GROUP option of PROC MIXED (42). An initial analysis, keeping assay repetition a fixed effect, determined that there was no effect of repetition $(P=$ $0.45)$ but there was an effect of repetition-treatment $(P=0.01)$ due to differences in broth control responses during the second repetition. Because the assays were conducted at different seasons, this could account for the differences in assay repetitions; thus, the 
three repetitions were combined. Additionally, there were effects of genetic background $(P<0.01)$ and genetic background-treatment interactions $(P=0.01)$. Therefore, results from $\mathrm{RTx} 430$ and Wheatland were analyzed separately. Least squares means (LSM) and standard error (SE) are reported.

$F$. thapsinum peduncle inoculations of new $\mathbf{b m r}$ lines. The bmr mutants 38, 100, 706, 1107, 1168, 1937, and bmr2-2 were identified from an ethyl methanesulfonate-mutagenized population of wild-type BTx623 and identified based on leaf midrib phenotype (53). Lines were received as $\mathrm{M}_{4} \mathrm{~s}$ of mutagenized grain then were selfed twice (706 and $b m r 2-2$ ) or three times (all other lines). Plants were grown from greenhouse-produced grain as described above. Plants were inoculated essentially as previously described (22). Peduncles of plants at anthesis (defined as half the anthers exerted) were wounded with a surface-disinfested awl by gently forming a shallow hole, and a toothpick with either a fungal broth culture or sterile broth was inserted into the hole. Eighteen days following inoculation, the peduncle was split longitudinally and the length of the red to purple discoloration (the lesion) was measured.

Fungus or broth-and-toothpick cultures were prepared as described above; all inocula for each assay were prepared at once. Greenhouse-grown grain were sown into soil mix in $25.4-\mathrm{cm}$ pots. The new bmr lines had differing germination and development rates. Inoculations occurred at the same time; therefore, the plant-

\section{A RTx430}

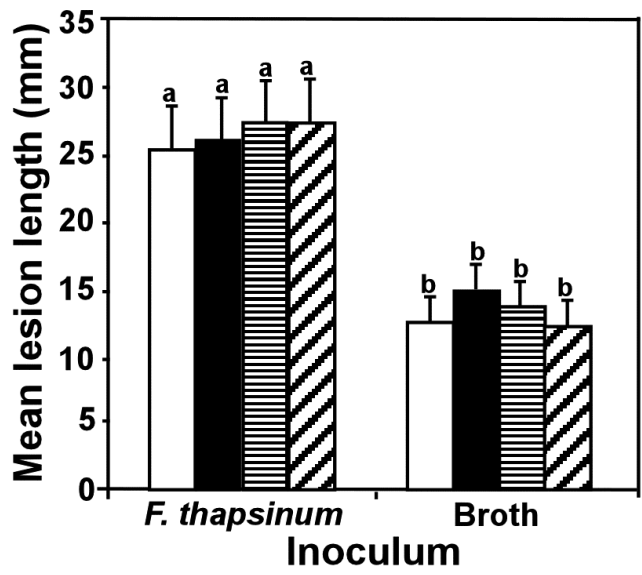

B Wheatland

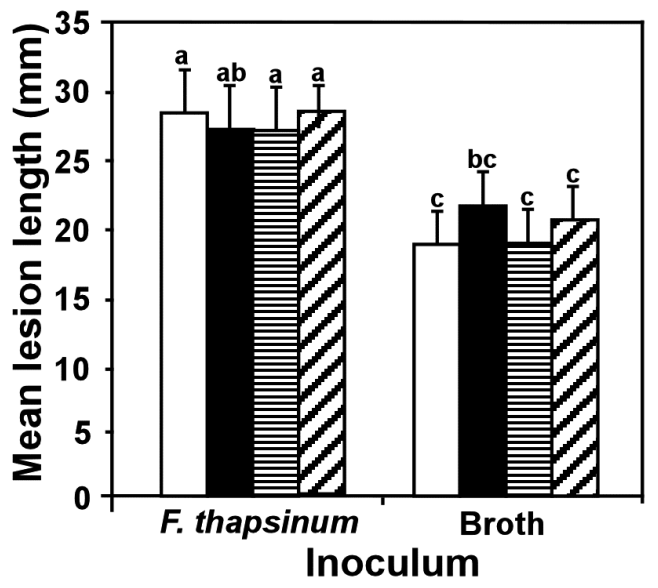

wild-type $\square$ bmr6 bmr12目 bmr6 bmr12У

Fig. 1. Fusarium thapsinum and control stalk inoculations of bmr6, bmr12, and bmr6 bmr12 double-mutant lines in two genetic backgrounds. Mean lesion lengths and positive standard errors resulting on near isogenic bmr lines in the genetic backgrounds A, RTX430 and B, 'Wheatland'. Plants were inoculated with toothpicks incubated with $F$. thapsinum or broth, using an optimized inoculation technique (see Materials and Methods). Lengths of discolorations resulting on split stalks were measured. Bars indicated with the same letter are not significantly different. ings were staggered. Two assays were performed. For the first assay, lines $38,100,1107,1168,1937$, and $b m r 2-2$ and wild-type BTx623 were screened. Line 100 was planted 107 days prior to inoculation, lines 1107 and 1168 were planted 100 days prior to inoculation, lines $b m r 2-2$ and 1168 were planted 95 days prior to inoculation, and line 38 and BTx623 were planted 85 days prior to inoculation. For the second assay, lines 706, 1107, 1168, 1937, and BTx623 were screened. Line 1937 was planted 116 days prior to inoculation, grain of lines 706 and 1107 were sown 100 days prior to inoculation, line 1168 was planted 92 days prior to inoculation, and seed of BTx623 were sown 85 days prior to inoculation. The assays were conducted October 2011 through March 2012 and October 2012 through February 2013. Each assay was analyzed using PROC MIXED procedure of SAS/STAT software (42) and results from the first assay were used to determine which lines to reexamine in the second assay; the $b m r$ lines were chosen because the first assay results suggested that there may be differences in responses when compared with BTx623. Lines 1107, 1168, and 1937 and the parental cultivar BTx623 were screened in both assays; therefore, the data were combined and analyzed as above. The experimental designs for each assay were six randomized complete blocks with seven (assay number 1) or five (assay number 2) plant genotypes and two (fungal or broth) treatments. Due to a significant Levene's test of HoV, the REPEATED/GROUP option of PROC MIXED (42) was included so that all levels or values were estimated separately. LSM and SE are reported.

The assays were combined for lines 1107, 1168, and 1937 and the wild-type BTx623. When analyzed with assay as a fixed effect, there was a significant assay effect-assay treatment interaction $(P$ $\leq 0.01)$ but there were no significant assay-entry or assay-entrytreatment interactions $(P \geq 0.20)$, suggesting that environmental factors may have affected the plant response to the pathogen but not plant genotype. LSM and SE are reported.

Response of in vitro fungal growth to phenolic compounds. $F$. thapsinum (isolate FRC-M-3790), $F$. verticillioides, $F$. solani, $C$. lunata, Alternaria sp., F. armeniacum, F. pallidoroseum, F. proliferatum, and $M$. phaseolina were grown on peptone-glucose agar (PGA) medium with one of the following compounds: ferulic acid (trans-4-hydroxy-3-methoxycinnamic acid; FA), vanillic acid (4hydroxy-3methoxybenzoic acid; VA), sinapic acid (3,5-dimethoxy4-hydroxycinnamic acid; SA), syringic acid (3,5-dimethoxy-4hydroxybenzoic acid; SyrA), or caffeic acid (3,4-dihydroxycinnamic acid; CafA). FA was purchased from TCI America and all others from Sigma-Aldrich. The compounds were added to autoclaved, molten PGA as stocks made in methanol (MeOH; 100 mM SA) or ethanol (EtOH; $200 \mathrm{mM} \mathrm{FA,} 250 \mathrm{mM} \mathrm{VA,} 100 \mathrm{mM}$ SyrA, or $250 \mathrm{mM}$ CafA). For each phenolic, a range of concentrations was screened and then a subset of concentrations was chosen to conduct the assay. Amounts of $\mathrm{MeOH}$ or $\mathrm{EtOH}$ were kept constant for each phenolic. Full-strength PGA is $1 \%$ glucose, $0.5 \%$ peptone, $7 \mathrm{mM}$ potassium phosphate monobasic, $2 \mathrm{mM}$ magnesium sulfate heptahydrate, and $2.2 \%$ agar per liter. Peptone and agar were purchased from Becton, Dickinson and Co. and glucose and salts from Fisher Scientific. Media containing phenolic solution or alcohol was dispensed into $35-\mathrm{mm}$ petri dishes. Plates with different concentrations of a given phenolic were color coded. Growth rates of each fungus on PGA and PGA with $3.5 \% \mathrm{EtOH}$, $7.5 \% \mathrm{EtOH}$, or $8 \% \mathrm{MeOH}$ added when grown at $25^{\circ} \mathrm{C}$ were compared using SAS/STAT software (42). F. pallidoroseum and $F$. verticillioides were affected by growth on both concentrations of EtOH $(P \leq 0.06)$. On $3 \%$ EtOH/97\% PGA, F. pallidoroseum grew at 2.1 versus $2.4 \mathrm{~mm} \mathrm{day}^{-1}$ on $97 \%$ PGA, and growth rates of $F$. verticillioides were 2.8 versus $3.4 \mathrm{~mm} \mathrm{day}^{-1}$, respectively. Growth for each fungus on $7.5 \% \mathrm{EtOH} / 92.5 \%$ PGA was similar to $3.5 \%$ EtOH. No fungi were negatively affected by growth on $8 \%$ $\mathrm{MeOH} / 92 \%$ PGA but $F$. proliferatum grew significantly faster $(P=$ $0.05)$ on $\mathrm{MeOH}: 3.3 \mathrm{~mm}$ day $^{-1}$ versus $2.8 \mathrm{~mm} \mathrm{day}^{-1}$ without $\mathrm{MeOH}$. This analysis demonstrated that the addition of these two alcohols could affect growth rates, although neither significantly impacted the assays. 
Preparation of fungi for inoculation of plates for radial growth bioassays was conducted as follows. A suspension of conidial or mycelial fragments was prepared and spread onto the surface of two plates containing full-strength PGA medium prepared in 35$\mathrm{mm}$ petri dishes. The pairs of plates were numbered 1 through 9 and order of inoculations was randomized for each assay. The inoc-

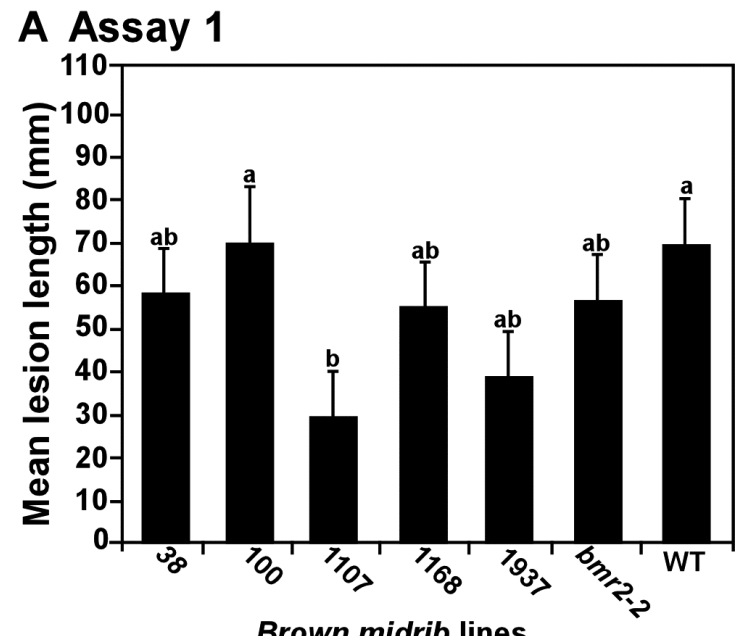

B Assay 2

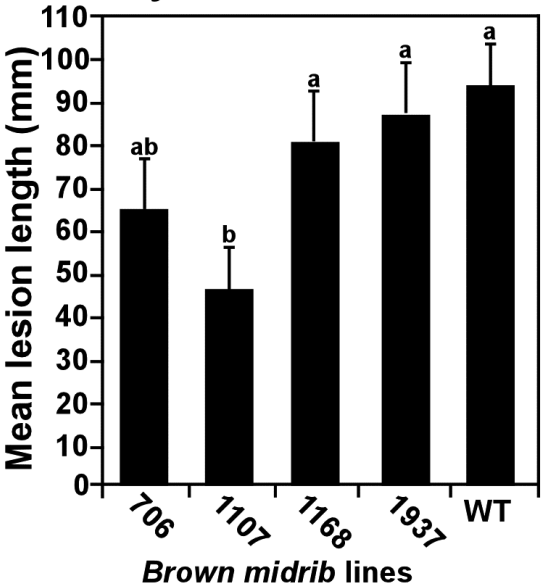

\section{Combined assays}

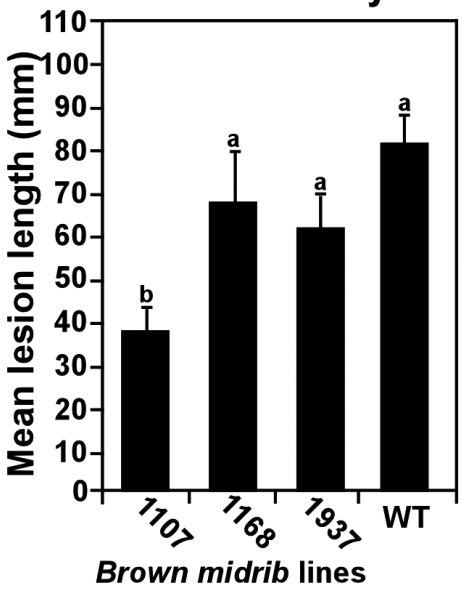

Fig. 2. Response of new $b m r$ lines derived from an ethyl methanesulfunatemutagenized population to Fusarium thapsinum peduncle inoculations. Mean lesion lengths and positive standard errors resulting from toothpick inoculations of lines $\mathbf{A}$, 38, 100, 1107, 1168, bmr2-2, and wild-type (WT) BTx623; B, 706, 1107, 1168, 1937, and WT; and C, combined assays for 1107, 1168, 1937, and WT. Plants were inoculated with toothpicks incubated with $F$. thapsinum or broth. Lengths of discolorations resulting on split peduncles were measured. Bars indicated with the same letter are not significantly different. ulated plates were incubated 48 to $66 \mathrm{~h}$ at room temperature in a moist chamber, after which a layer of mycelium covered the medium. A number 1 cork borer (diameter $=4 \mathrm{~mm}$ ), surface disinfested, was used to cut agar disks from each inoculum plate. One agar disk was placed on the edge of each test medium. Three plates per treatment (e.g., the treatments were plates containing differing

\section{A Ferulic acid}

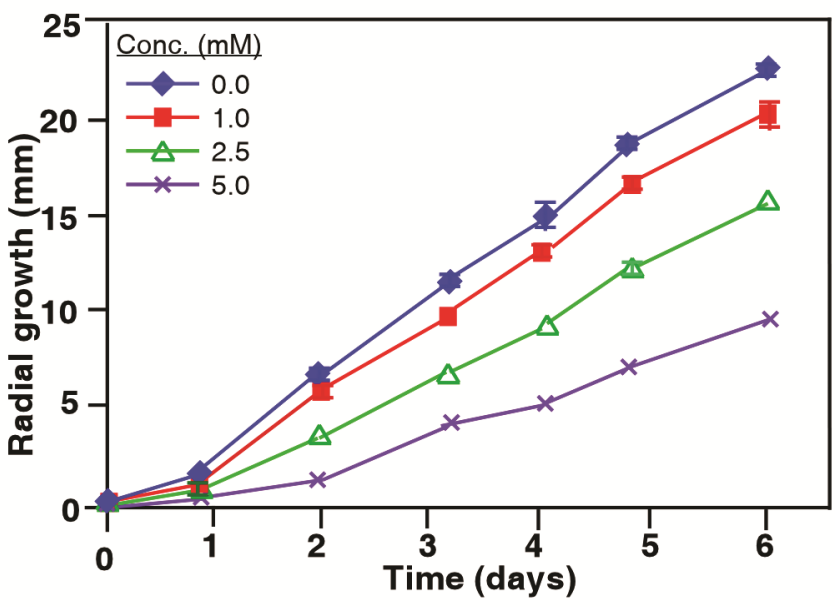

B Syringic acid

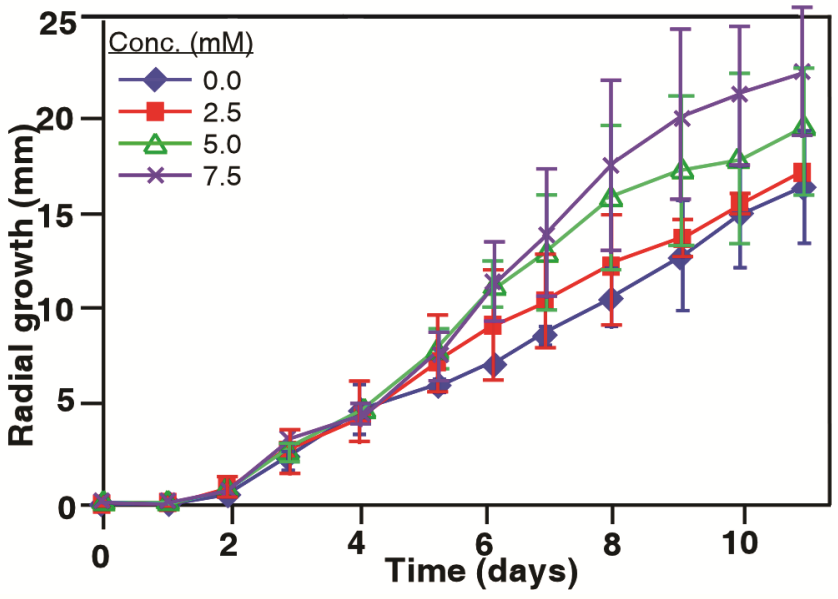

C Caffeic acid

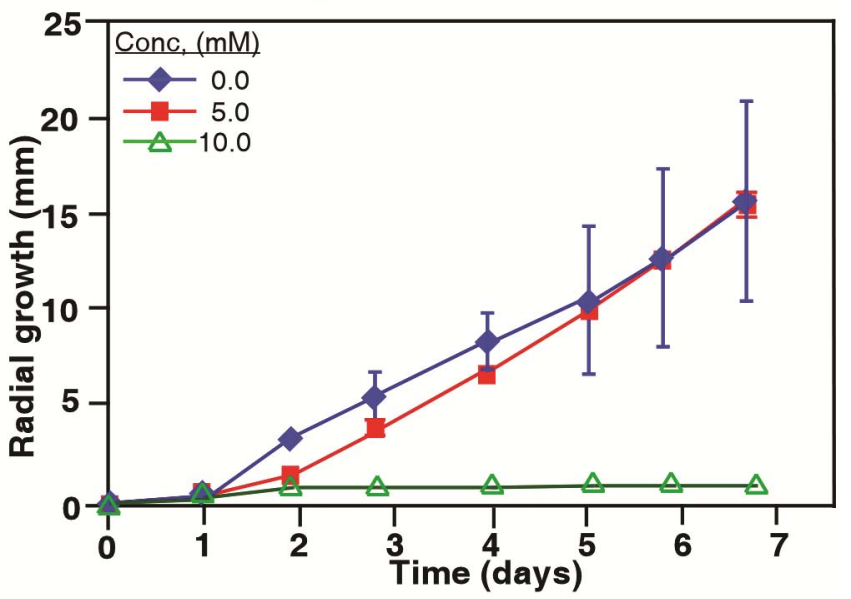

Fig. 3. Radial growth curves (millimeters per day) of Fusarium thapsinum grown on different concentrations $(\mathrm{mM})$ of phenolic compounds. F. thapsinum was grown on agar medium amended with $\mathbf{A}$, ferulic acid, added in $2.4 \%$ ethanol (EtOH); $\mathbf{B}$, syringic acid, added in $7.5 \% \mathrm{EtOH}$; and C, caffeic acid, added in $4 \% \mathrm{EtOH}$. Means and standard deviations $\geq 0.5$ are shown. Note that time in days differ for different phenolics. 
concentrations of phenolics) were prepared for each fungus. Inoculated plates were incubated at $25^{\circ} \mathrm{C}$ in a moist chamber. To measure radial growth, radius from the agar plug was scored on the back of each plate using a scalpel. Daily, beginning at 0 days (the edge of the agar disk), growth was indicated by scoring along the radius under a dissecting microscope. Each assay tested fungal response to one phenolic; two, three, or four repetitions were conducted for each phenolic. Line graphs illustrating response of F. thapsinum to FA, SyrA, and CafA were constructed by calculating means and standard deviations at each time point for a representative assay.

The experimental design was completely randomized and each treatment combination was replicated three times. The first two repetitions to test fungal responses to FA and VA were somewhat

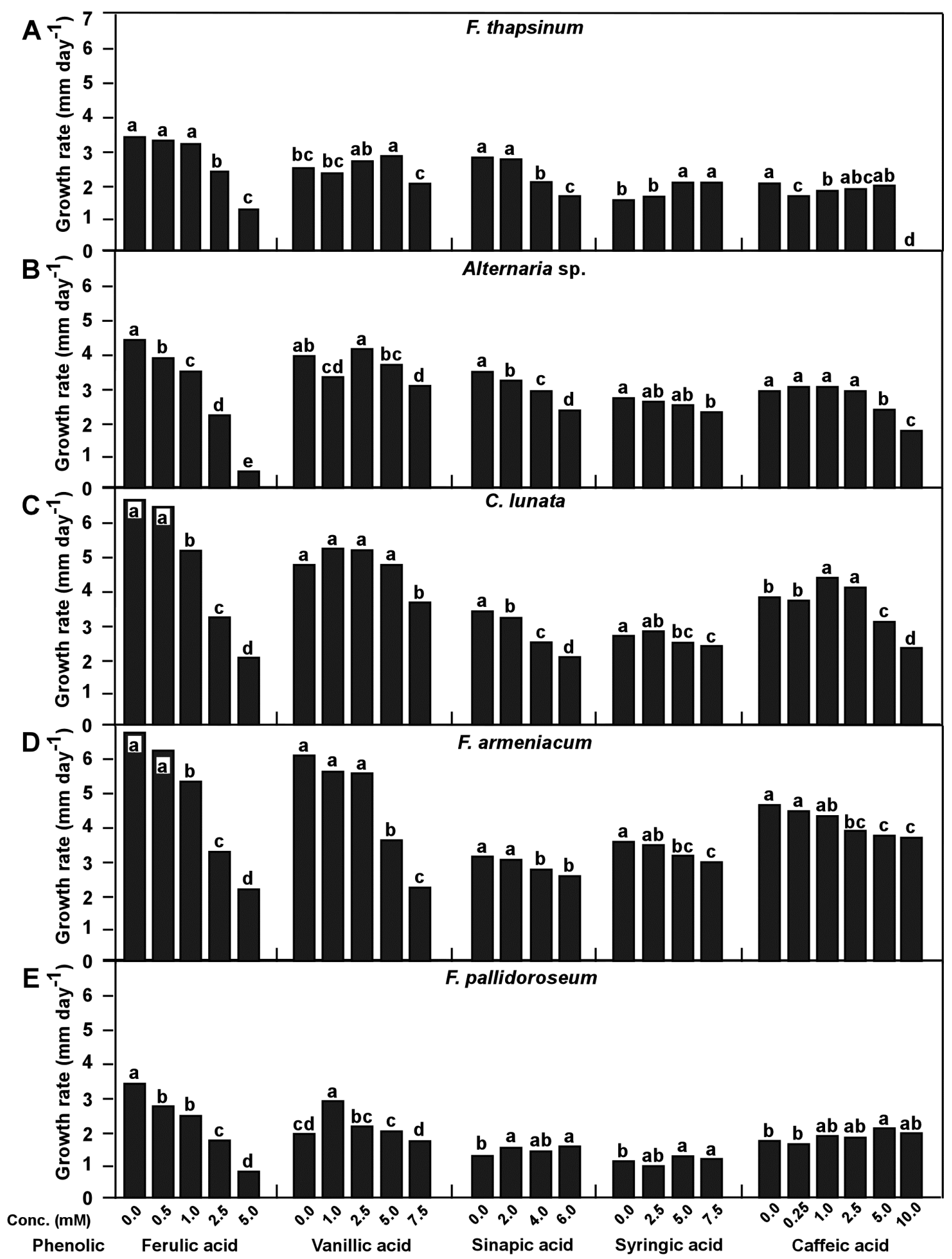

Fig. 4. Histograms representing growth rates (millimeters per day) of sorghum fungi grown at different concentrations (mM) of phenolic compounds. Fungi were grown on agar medium amended with ferulic acid (added in $2.4 \%$ ethanol [EtOH]), vanillic acid (added in 3\% EtOH), sinapic acid (added in $8 \%$ methanol), syringic acid (added in $7.5 \%$ $\mathrm{EtOH}$ ), or caffeic acid (added in $4 \% \mathrm{EtOH}$ ) at differing concentrations (as indicated on x-axis). Bars with differing letters when comparing growth of a given fungus on different concentrations of a given phenolic are significantly different at $P \leq 0.05$. Standard errors are from 0.0 to 0.2 . A, Fusarium thapsinum; $\mathbf{B}$, Alternaria sp.; C, Curvularia lunata; D, F. armeniacum; E, F. pallidoroseum; F, F. proliferatum; G, F. solani; H, F. verticillioides; and I, Macrophomina phaseolina. (continued on next page) 
variable whereas the two repetitions to test responses to SyrA, SA, and CafA were consistent. Therefore, four repetitions of the assay to test fungal response to FA were conducted and three were conducted for VA, whereas tests for responses to SyrA, SA, and CafA were conducted twice. Data were analyzed using PROC MIXED procedure of SAS/STAT software (42). Response to each phenolic was analyzed separately. Repetitions of each assay were considered random effects. The KENWARD-ROGER option was specified to calculate denominator degrees of freedom because of heterogeneous variances and to reduce standard error and $F$-statistic bias $(25,30)$. LSM were generated and the differences among media LSM were compared using the DIFF option. Phenolic concentration was considered a fixed effect in the model used to analyze radial growth, and measurements across time on the same plate were considered repeated measures. The KENWARD-ROGER option was again specified for estimating degrees of freedom. A linear model was used to estimate growth rate on each concentration. Slopes were output using the SOLUTION option and the NOINT option was used to force the intercept to zero at the initiation of the experiment. Confidence intervals for the slopes were set at $P=0.05$ using the CL option. Comparisons among phenolic concentrations were made using single degree-of-freedom contrasts.

\section{Results}

$F$. thapsinum stalk inoculations of near-isogenic bmr lines. There was a significant plant genotype-treatment interaction, apparently due to differences in genotype response to the broth control $(P<0.01)$ but not to the fungal treatment $(P=0.55)$. Therefore, each genetic line is shown separately in Figure 1. There were

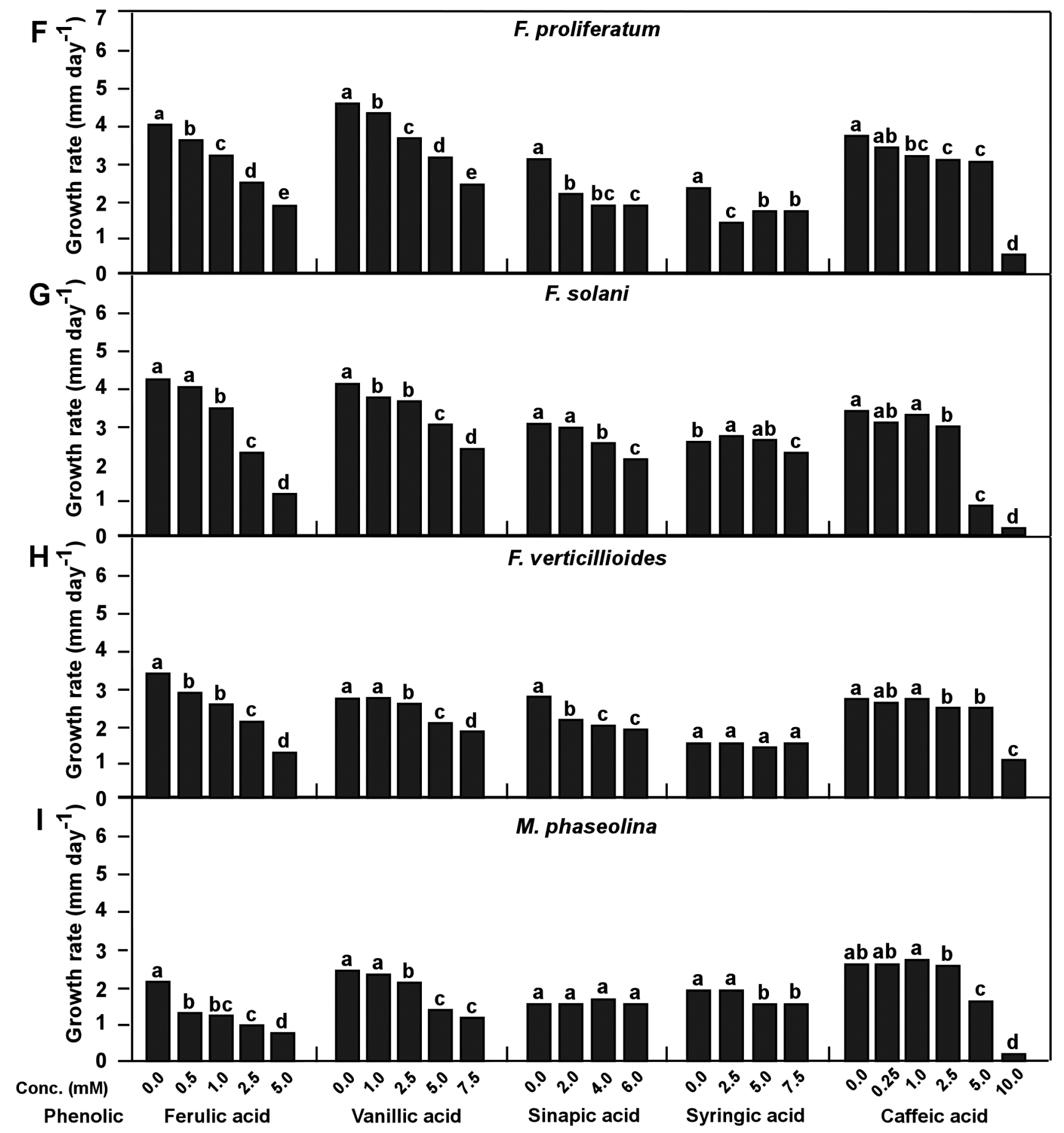

Fig. 4. (continued from preceding page) 
no significant differences in mean lesion lengths of $b m r$ lines and the wild type when inoculated with the fungus. However, in the case of Wheatland bmr6, mean lesion length resulting from inoculation with the fungus was not significantly different from the broth inoculation $(P=0.06)$ (Fig. 1B); this was not the case when comparing fungal and broth inoculations of RTx430 bmr6 plants $(P<0.01)$ (Fig. 1A).

$F$. thapsinum peduncle inoculations of new $\mathrm{bmr}$ lines. In the first assay, six $b m r$ lines were screened and mean lesion lengths were compared with wild-type BTx623 (Fig. 2A); none of the lines tested was more susceptible to $F$. thapsinum than BTx623. One line (1107) had mean lesion length significantly smaller than that on the wild-type line $(P=0.01)$. This line and two other promising lines (1168 and 1937) were tested in a second assay that included a seventh newly identified $b m r$ line (706) obtained from the same mutant population (Fig. 2B). Inoculations of the $b m r$ lines 706, 1168 , and 1937 yielded mean lesion lengths not significantly different than the wild-type line $(P \geq 0.07)$, and line 1107 again had mean lesion lengths significantly smaller than the wild type $(P<$ 0.01). Results from both assays were combined for lines 1107, 1168, 1937, and BTx623 (Fig. 2C), further supporting the observation that mean lesion lengths were not significantly different from the wild-type when inoculated with $F$. thapsinum, except for 1107, which consistently had shorter mean lesion length than the wild type.

Effects of lignin biosynthetic pathway intermediates on in vitro growth of $\boldsymbol{F}$. thapsinum. Representative growth curves of $F$. thapsinum isolate FRC-M-3790 grown on FA, SyrA, and CafA are shown in Figure 3 and growth rates for $F$. thapsinum grown on FA, VA, SA, SyrA, and CafA are shown graphically in Figure 4A. When grown on varying concentrations of FA, the fungus was inhibited at higher concentrations (Fig. 3A); significant inhibition $(P<0.01)$ occurred at $2.5 \mathrm{mM}$ (Fig. 4A). VA appeared to stimulate growth of $F$. thapsinum; however, significant differences were not observed between the negative control and the lower concentration of VA (Fig. 4A). The highest concentration of VA significantly reduced the growth rate of $F$. thapsinum $(P<0.01)$; whether this is biologically relevant is not clear. Higher concentrations of SA $(\geq 4$ $\mathrm{mM})$ also reduced $F$. thapsinum growth rates $(P<0.01)$ when compared with the negative control (MeOH alone; Fig. 4A). The addition of 5.0 or $7.5 \mathrm{mM}$ SyrA to the medium resulted in significantly greater growth rates of $F$. thapsinum ( $P \leq 0.01$; Fig. 4A). Inhibition of $F$. thapsinum by CafA occurred only at the highest concentration (10 mM; Figs. 3C and 4A). The biological relevance of inhibition at these higher concentrations of phenolics is presently unclear.

Response of in vitro growth of fungi associated with sorghum to lignin biosynthetic pathway intermediates. All of the fungi tested were significantly inhibited by FA at the lower concentrations tested: Alternaria sp., F. pallidoroseum, $F$. proliferatum, $F$. verticillioides, and $M$. phaseolina at $0.5 \mathrm{mM}$ and C. lunata, F. armeniacum, and F. solani at $1.0 \mathrm{mM}$ (Fig. 4B-I; Supplementary Table S1). The growth rates of $C$. lunata, $F$. armeniacum, $F$. pallidoroseum, and $M$. phaseolina were unaffected by VA, SA, and SyrA at the lower concentrations tested (Fig. 4C-E and I). For two closely related species, $F$. proliferatum and $F$. verticillioides, growth rates were similarly inhibited by the lower concentrations of FA, VA, and SA tested, unlike $F$. thapsinum, another closely related species (Fig. 4AF and $\mathrm{H}$ ). Growth rate of $F$. solani was significantly inhibited by VA $(\geq 1.0 \mathrm{mM})$ and, at lower concentrations of SyrA, the growth of $F$. solani was induced (Fig. 4G).

\section{Discussion}

This study demonstrated that none of the $b m r$ lines tested were more susceptible than their corresponding wild-type lines to $F$. thapsinum. The bmr6, bmr12, and bmr6 bmr12 double-mutant lines in the backgrounds Wheatland and RTx430 are well-developed lines with the goal to provide genetic stocks for comparison of effects of these genes conferring reduced lignin $(36,37)$ and other beneficial consequences, such as increased digestibility and improved cellulosic ethanol yield $(13,31)$. To further demonstrate that the lines are also not more susceptible to $F$. thapsinum stalk rot under controlled conditions enhances the usability of these lines. Additionally, these results indicated that bmr line 1107 (Fig. 2) may have increased resistance to the highly virulent stalk pathogen $F$. thapsinum. At the present time, the genetic studies have not been completed to establish whether there is an association of $b m r$ with increased resistance. Nonetheless, bmr line 1107 might be promising for breeding for stock rot resistant, reduced-lignin sorghum.

Previously, peduncle inoculations of bmr6 and bmrl2 sorghum lines with significantly reduced lignin in six genetic backgrounds demonstrated that none of the lines were more susceptible than their respective wild-type parent, and bmr6 or bmrl2 lines were more resistant to $F$. thapsinum than their respective wild-type lines in four backgrounds (16). Infections of the peduncle could result in its breakage and loss of the grain (14). To simulate infection at the base of the stalk by stalk rot fungi, which can result in lodging under field conditions, (7), a greenhouse stalk inoculation technique was developed and optimized for inoculations with $F$. thapsinum. This assay included a broth control inoculation to assess response to wounding commonly observed with sorghum (15). Differences in wound response were observed between the two genetic backgrounds tested (Fig. 1); nonetheless, there was no indication that any of the $b m r$ lines, including the double-mutant line, were more susceptible to $F$. thapsinum infection than nearisogenic wild-type lines.

It was previously observed that single- and double-mutant $b m r$ lines exhibited changes in levels of certain phenolics within stalks of mature plants, as compared with near-isogenic wild-type parents (33). It was proposed that these changes may contribute to lack of susceptibility or, in the case of some $b m r$ lines, increased resistance, observed in this and previous studies $(16,19)$. One possible effect of the change in phenolic composition in the plant is to directly inhibit growth of fungal pathogens. In the current work, this was addressed by growing $F$. thapsinum and eight other fungi found in association with sorghum with phenolics involved in the lignin pathway, in which cellular levels may be perturbed in $\mathrm{bmr}$ mutants (33). With regard to eight of the sorghum isolates that included grain (Alternaria sp., $C$. lunata, and $F$. proliferatum), leaf ( $F$. armeniacum and $F$. pallidoroseum), stalk ( $F$. verticillioides and $M$. phaseolina), and soil ( $F$. solani) isolates, they were all significantly reduced in growth rate on the lower concentrations of FA tested (Fig. 4B-I). Palmer et al. (33) previously showed that FA was significantly increased in bmr6 in both backgrounds and in the Wheatland double-mutant bmr6 bmr12, relative to respective wildtype lines (33). In the case of Wheatland bmr6, the mean level of FA was reported as $856 \mu \mathrm{g} \mathrm{g}^{-1}$ dry weight, approximately nine times that of wild-type Wheatland plants. Estimating water content in sorghum at $80 \%$, this calculates to $0.88 \mathrm{mM}$ FA, well within the significantly inhibitory levels observed in the present study for the eight fungi, other than F. thapsinum (Fig. 4). Ferulic acid has also been suggested as playing a role in inhibition of $F$. graminearum on maize or wheat $(3,6)$.

In the present study, two closely related species, $F$. verticillioides and $F$. proliferatum (50), were inhibited by lower concentrations of several ( $F$. verticillioides FA, VA, and SA) or all five phenolic compounds tested. Along with increased levels of FA in some $b m r$ lines, concentrations of soluble VA and SA were previously shown to be similarly and significantly increased in bmr6 (Wheatland and RTx430), bmr12 (RTx430), and double-mutant (Wheatland and RTx430) lines (33). Soluble concentrations of SyrA were also significantly increased in $b m r 6$ and double-mutant lines of Wheatland and significantly increased in $b m r 6 \mathrm{RT} \times 430$ lines but decreased in bmr12 and double-mutant RTx430 lines. Meanwhile, soluble CafA concentrations were significantly increased in bmr6 and bmrl2 but not the double-mutant Wheatland lines, while bmr6 and doublemutant RTx430 lines had significantly reduced CafA levels compared with corresponding wild-type lines (33). Increased levels of VA, SA, SyrA, and CafA were not as great as that observed for FA in Wheatland bmr6 lines, as described above. In another study, it was also observed that some $b m r$ lines had decreased infection by 
$F$. verticillioides (inoculated peduncles) and $F$. proliferatum (naturally infected grain) (19). If VA, SA, SyrA, and CafA are involved in increased resistance, they may have a synergistic effect with one another, other phenylpropanoid intermediates or derivatives, or other pathways involved in defense responses (46).

$F$. thapsinum, which is closely related to both $F$. proliferatum and $F$. verticillioides (28), was only inhibited at the higher concentrations of FA, VA, SA, SyrA, and CafA. This observation suggests that $F$. thapsinum is relatively tolerant to changes in cellular levels of these compounds. Changes in concentrations of phenolic metabolites in $b m r$ plants may contribute to resistance to $F$. verticillioides, $F$. solani, $F$. armeniacum, and Alternaria sp. previously observed in infected peduncles (19); however, the resistance to $F$. thapsinum, observed following peduncle inoculations $(16,19$, and the present work) may be due to factors other than direct involvement by the phenolic metabolites discussed here. It was previously proposed that $F$. thapsinum is highly specific to sorghum $(18,29)$ whereas other members of the G. fujikuroi species complex, which includes $F$. proliferatum and $F$. verticillioides, infect multiple grass species. F. thapsinum may have become tolerant to varying levels of phenolic compounds found in highly diverse sorghum genotypes. We previously proposed that mutations in the lignin pathway, which can elevate concentrations of phenolic intermediates and compounds derived from the lignin pathway (33), may cause a shift of these metabolites toward other phenylpropanoid pathway branches such as aromatic phytoalexins or salicylic acid that are involved in defense (19).

In summary, this study has provided further evidence that $b m r$ does not result in increased stalk disease caused by $F$. thapsinum. By screening new bmr lines for response to $F$. thapsinum, it has been revealed that a new $b m r$ mutant may be more resistant to this pathogen than the wild-type parent. This study also has provided in vitro evidence that FA can inhibit several fungi, providing a possible explanation for resistance previously observed in some $b m r$ lines. However, the highly virulent sorghum pathogen $F$. thapsinum is relatively tolerant to this and to four other phenolics, suggesting that multiple mechanisms of resistance may be at play in these lines.

\section{Acknowledgments}

This research was supported by a National Institute of Food \& Agriculture grant number 2011-67009-30026 and additional funding from USDA-ARS, CRIS project number 5440-21220-027-00D. We thank J. Toy for production of greenhouse-grown grain and P. O'Neill for overseeing greenhouse experiments and for conducting statistical analyses.

\section{Literature Cited}

1. Abramson, M., Shoseyov, O., and Shani, Z. 2010. Plant cell wall reconstruction toward improved lignocellulosic production and processability. Plant Sci. 178:61-72.

2. Angelini, R., Tisi, A., Rea, G., Chen, M. M., Botta, M., Federico, R., and Cona, A. 2008. Involvement of polyamine oxidase in would healing. Plant Physiol. 146:162-177.

3. Assabgui, R. A., Reid, L. M., Hamilton, R. I., and Arnason, J. T. 1993. Correlation of kernel (E)-ferulic acid content of maize with resistance to Fusarium graminearum. Phytopathology 83:949-953.

4. Bird, P. M. 1988. The role of lignification in plant disease. Pages 523-535 in: Experimental and Conceptual Plant Pathology, vol. 3. R. S. Singh, U. S. Singh, W. M. Hess, and D. J. Weber, eds. Oxford and IBH Publishing Co., Pvt., Ltd., New Delhi, India.

5. Bout, S., and Vermerris, W. 2003. A candidate-gene approach to clone the sorghum Brown midrib gene encoding caffeic acid $O$-methyltransferase. Mol. Gen. Genomics 269:205-214.

6. Boutigny, A.-L., Barreau, C., Atanasova-Penichon, V., Verdal-Bonnin, M.N., Pinson-Gadais, L., and Richard-Forget, F. 2009. Ferulic acid, an efficient inhibitor of type B trichothecene biosynthesis and Tri gene expression in Fusarium liquid cultures. Mycol. Res. 113:746-753.

7. Bramel-Cox, P. J., and Claflin, L. E. 1989. Selection for resistance to Macrophomina phaseolina and Fusarium moniliforme in sorghum. Crop Sci. 29:1468-1472.

8. Bunting, A. H. 1990. The pleasures of diversity. Biol. J. Linn. Soc. Lond. 39:79-87.

9. Campbell, M. M., and Sederoff, R. R. 1996. Variation in lignin content and composition: Mechanisms of control and implication for the genetic improvement of plants. Plant Physiol. 110:3-13.

10. Castor, L. L., and Frederiksen, R. A. 1982. Grain deterioration in sorghum. Pages 163-169 in: Proc. Int. Symp. Sorghum Grain Quality. L. W. Rooney and D. S. Murty, eds. ICRISAT Center, Patancheru A.P., India.

11. Corredor, D. Y., Salazar, J. M., Hohn, K. L., Bean, S., Bean, B., and Wang, D. 2009. Evaluation and characterization of forage sorghum as feedstock for fermentable sugar production. Appl. Biochem. Biotechnol. 158:164-179.

12. Das, I. K., Prabhakar, and Indira, S. 2008. Role of stalk-anatomy and yield parameters in development of charcoal rot caused by Macrophomina phaseolina in winter sorghum. Phytoparasitica 36:199-208.

13. Dien, B. S., Sarath, G., Pedersen, J. F., Sattler, S. E., Chen, H., FunnellHarris, D. L., Nichols, N. N., and Cotta, M. A. 2009. Improved sugar conversion and ethanol yield for forage sorghum (Sorghum bicolor L. Moench) lines with reduced lignin content. Bioenergy Res. 2:153-164.

14. Frederiksen, R. A., and Odvody, G. N. 2000. Compendium of Sorghum Diseases, 2nd ed. American Phytopathological Society, St. Paul, MN.

15. Funnell, D. L., and Pedersen, J. F. 2006. Association of plant color and pericarp color with colonization of grain by members of Fusarium and Alternaria in near-isogenic sorghum lines. Plant Dis. 90:411-418.

16. Funnell, D. L., and Pedersen, J. F. 2006. Reaction of sorghum lines genetically modified for reduced lignin content to infection by Fusarium and Alternaria spp. Plant Dis. 90:331-338.

17. Funnell-Harris, D. L., and Pedersen, J. F. 2008. Inoculation strategies to assess biological interactions between Fusarium and Alternaria species infecting sorghum. Can. J. Plant Pathol. 30:404-413.

18. Funnell-Harris, D. L., and Pedersen, J. F. 2011. Presence of Fusarium spp. in air and soil associated with sorghum fields. Plant Dis. 95:648-656.

19. Funnell-Harris, D. L., Pedersen, J. F., and Sattler, S. E. 2010. Alteration in lignin biosynthesis restricts growth of Fusarium spp. in brown midrib sorghum. Phytopathology 100:671-681.

20. Funnell-Harris, D. L., Prom, L. K., and Pedersen, J. F. 2013. Isolation and characterization of the grain mold fungi, Cochliobolus and Alternaria spp., from sorghum using semi-selective media and DNA sequence analyses. Can. J. Microbiol. 99:87-96.

21. Gatto, M. A., Ippolito, A., Linsalata, V., Carscarano, N. A., Nigro, F., Vanadia, S., and Di Venere, D. 2011. Activity of extracts from wild edible herbs against postharvest fungal diseases of fruit and vegetables. Postharvest Biol. Technol. 61:72-82.

22. Jardine, D. J., and Leslie, J. F. 1992. Aggressiveness of Gibberella fujikuroi (Fusarium moniliforme) isolates to grain sorghum under greenhouse conditions. Plant Dis. 76:897-900.

23. Karp, A., and Shield, I. 2008. Bioenergy from plants and the sustainable yield challenge. New Phytol. 179:15-32.

24. Kayode, A. P. P., Linnemann, A. R., Nout, M. J. R., Hounhouigan, J. D. Stomph, T. J., and Smulders, M. J. M. 2006. Diversity and food quality properties of farmers' varieties of sorghum from Benin. J. Sci. Food Agric. 86:1032-1039.

25. Kenward, M. G., and Roger, J. H. 1997. Small sample inference for fixed effects from restricted maximum likelihood. Biometrics 53:983-997.

26. Klittich, C. J. R., Leslie, J. F., Nelson, P. E., and Marasas, W. F. O. 1997. Fusarium thapsinum (Gibberella thapsina): A new species in section Liseola from sorghum. Mycologia 89:643-652.

27. Lanoue, A., Burlat, V., Henkes, G. J., Koch, I., Schurr, U., and Rose, U. S. R. 2010. De novo biosynthesis of defense root exudates in response to Fusarium attack in barley. New Phytol. 185:577-588.

28. Leslie, J. F., Zeller, K. A., Lamprecht, S. C., Rheeder, J. P., and Marasas, W. F. O. 2005. Toxicity, pathogenicity, and genetic differentiation of five species of Fusarium from sorghum and millet. Phytopathology 95:275-283.

29. Leslie, J. F., Zeller, K. A., Logrieco, A., Mule, G., Moretti, A., and Ritieni, A. 2004. Species diversity of and toxin production by Gibberella fujikuroi species complex strains isolated from native prairie grasses in Kansas. Appl Environ. Microbiol. 70:2254-2262.

30. Littell, R. C., Milliken, G. A., Stroup, W. W., Wolfinger, R. D., and Schabenberger, O. 2006. SAS for Mixed Models, Second Edition. SAS Institute, Inc., Cary, NC.

31. Oliver, A. L., Pedersen, J. F., Grant, R. J., Klopfenstein, T. J., and Jose, H. D. 2005. Comparative effects of the sorghum $b m r-6$ and $b m r-12$ genes: II. Grain yield, stover yield, and stover quality in grain sorghum. Crop Sci. 45:2240-2245.

32. Padule, D. N., and Salunkhe, D. K. 1984. Effects of diseases on yield and quality of grain sorghum. In: Nutritional and Processing Quality of Sorghum. D. K. Salunkhe, J. K. Chavan and S. J. Jadhav, eds. Oxford \& IBH Pub. Co., New Dehli, India.

33. Palmer, N. A., Sattler, S. E., Saathoff, A. J., Funnell, D., Pedersen, J. F., and Sarath, G. 2008. Genetic background impacts soluble and cell wall-bound aromatics in brown midrib mutants of sorghum. Planta 229:115-127.

34. Paterson, A. H., Bowers, J. E., Bruggmann, R., Dubchak, I., Grimwood, J., Gundlack, H., Haberer, G., Hellsten, U., Mitros, T., Poliakov, A., Schmutz, J., Spannagl, M., Tang, H., Wang, X., Wicker, T., Bharti, A. K., Chapman, J., Feltus, F. A., Gowik, U., Grigoriev, I. V., Lyons, E., Maher, C. A., Martis, M., Narechania, A., Otillar, R. P., Penning, B. W., Salamov, A. A., Wang, Y., Zhang, L., Carpita, N. C., Freeling, M., Gingle, A. R., Hash, C. T., Keller, B., Klein, P., Kresovich, S., McCann, M. C., Ming, R., Peterson, D. G., Mehboob-ur-Rahman, Ware, D., Westhoff, P., Mayer, K. F. X., Messing, J., and Rokhsar, D. S. 2009. The Sorghum bicolor genome and the diversification of grasses. Nature 457:551-556.

35. Pedersen, J. F., Funnell, D., Toy, J. J., Oliver, A. L., and Grant, R. J. 2006. 
Registration of seven forage sorghum genetic stocks near-isogenic for the brown midrib genes $b m r-6$ and $b m r-12$. Crop Sci. 46:490-491.

36. Pedersen, J. F., Funnell, D., Toy, J. J., Oliver, A. L., and Grant, R. J. 2006. Registration of twelve grain sorghum genetic stocks near-isogenic for the brown midrib genes bmr-6 and bmr-12. Crop Sci. 46:491-492.

37. Pedersen, J. F., Toy, J. J., Funnell, D., Sattler, S. E., Oliver, A. L., and Grant, R. J. 2008. Registration of BN611, AN612, BN612, and RN613 sorghum genetic stocks with staked $b m r-6$ and $b m r-12$. J. Plant Regist. 2:258-262.

38. Putnam, D. H., Lueschen, W. E., Kanne, B. K., and Hoverstad, T. R. 1991. A comparison of sweet sorghum cultivars and maize for ethanol production. J. Prod. Agric. 4:377-381.

39. Saballos, A., Ejeta, G., Sanchez, E., Kang, C. H., and Vermerris, W. 2009. A genomewide analysis of the cinnamyl alcohol dehydrogenase family in sorghum (Sorghum bicolor (L.) Moench) identifies SbCad2 as the Brown midrib6 gene. Genetics 181:783-795.

40. Saballos, A., Sattler, S. E., Sanchez, E., Foster, T. P., Xin, Z., Kang, C. H., Pedersen, J. F., and Vermerris, W. 2012. Brown midrib2 (Bmr2) encodes the major 4-coumarate: Coenzyme A ligase involved in lignin biosynthesis in sorghum, (Sorghum bicolor (L.) Moench). Plant J. 70:818-830.

41. Sarath, G., Mitchell, R. B., Sattler, S. E., Funnell, D., Pedersen, J. F., Graybosch, R. A., and Vogel, K. P. 2008. Opportunities and roadblocks in utilizing forages and small grains for liquid fuels. J. Ind. Microbiol. Biotechnol. 35:343-354.

42. SAS. 2002-2008. SAS/STAT software, version 9.2 of the SAS System for Windows. Copyright 2002-2008 SAS Institute Inc., Cary, NC.

43. Sattler, S. E., and Funnell-Harris, D. L. 2013. Modifying lignin to improve bioenergy feestocks: Strengthening the barrier against pathogens? Front. Plant Sci. 4:Article 70.

44. Sattler, S. E., Funnell-Harris, D. L., and Pedersen, J. F. 2010. Brown midrib mutations and their importance to the utilization of maize, sorghum, and pearl millet lignocellulosic tissues. Plant Sci. 178:229-238.

45. Sattler, S. E., Saathoff, A. J., Haas, E. J., Palmer, N. A., Funnell-Harris, D. L., Sarath, G., and Pedersen, J. F. 2009. A nonsense mutation in a cinnamyl alcohol dehydrogenase gene is responsible for the sorghum brown midrib6 phenotype. Plant Physiol. 150:584-595.

46. Shirasu, K., Nakajima, H., Rajasekhar, K., Dixon, R. A., and Lamb, C 1997. Salicylic acid potentiates and agonist dependent gain control that amplifies pathogen signals in activation of defense mechanisms. Plant Cell 9:261-270.

47. Tesso, T., Claflin, L. E., and Tuinstra, M. R. 2004. Estimation of combining ability for resistance to Fusarium stalk rot in grain sorghum. Crop Sci. 44:1195-1199.

48. Valette, C., Andary, C., Geiger, J. P., Sarah, J. L., and Nicole, M. 1998. Histochemical and cytochemical investigations of phenols in roots of banana infected by the burrowing nematode Radopholus similus. Phytopathology 88:1141-1148.

49. Venuto, B., and Kindiger, B. 2008. Forage and biomass feedstock production from hybrid forage sorghum and sorghum-sudangrass hybrids. Grassl. Sci. 54:189-196.

50. Visentin, I., Tamietti, G., Valentino, D., Portis, E., Karlovsky, P., Moretti, A., and Cardinale, F. 2009. The ITS region as a taxonomic discriminator between Fusarium verticillioides and Fusarium proliferatum. Mycol. Res. 113:1137-1145.

51. Wang, M. L., Zhu, C., Barkley, N. A., Chen, Z., Erpelding, J. E., Murray, S. C., Tuinstra, M. R., Tesso, T., Pederson, G., and Yu, J. 2009. Genetic diversity and population structure analysis of accessions in the US historic sweet sorghum collection. Theor. Appl. Genet. 120:13-23.

52. Wu, X., Staggenborg, S., Propheter, J., Rooney, L. W., Yu, J., and Wang, D. 2009. Features of sweet sorghum juice and their performance in ethanol fermentation. Ind. Crops Prod. 31:164-170.

53. Xin, Z., Wang, M. L., Barkley, N. A., Burow, G., Franks, C., Pederson, G., and Burke, J. 2008. Applying genotyping (TILLING) and phenotyping analyses to elucidate gene function in a chemically induced sorghum mutant population. BMC Plant Biol. 8:Article number 103.

54. Zegada-Lizarazu, W., and Monti, A. 2011. Energy crops in rotation. A review. Biomass Bioenergy 35:12-25. 